\title{
Assessment of directional accuracy of GNSS-Acoustic measurement using a slackly moored buoy
}

\author{
Misae Imano ${ }^{*}$ (D), Motoyuki Kido², Chie Honsho ${ }^{3}$, Yusaku Ohta ${ }^{3}$, Narumi Takahashi, ${ }^{4,5}$, Tatsuya Fukuda ${ }^{6}$,
}

Hiroshi Ochi ${ }^{6}$ and Ryota Hino ${ }^{3}$

\begin{abstract}
We assessed the positioning accuracy of GNSS-Acoustic (GNSS-A) measurement using a slackly moored buoy. A key feature of real-time buoy-based GNSS-A measurement is that positioning must be performed via single ranging from an arbitrary observation position and encompassing the drifting range of the buoy. In this study, slack-line mooring was employed to resist strong Kuroshio current of up to 5.5 knots in the Nankai Trough. During a year-long sea trial, the buoy drifted within a circle of $\sim 4000 \mathrm{~m}$ radius, which is much larger than the dimension of a seafloor transponder array. In the sea trial, more than 500 successful regular and on-demand ranging measurements were obtained at various observation positions. The results show that the horizontal positioning accuracy (2ఠ) of the array for single ranging was $46 \mathrm{~cm}$ when the buoy was inside the array and $97 \mathrm{~cm}$ when it was outside the array. These accuracies are comparable to those achieved through single ranging in traditional ship-based surveys at the same site. In addition to the distance dependency, we observed directivity in the accuracy, depending on the geometry between an observation point and seafloor transponders. To interpret the accuracy degradation and directivity as a function of observation position, we calculated error ellipses using a dilution-of-precision (DOP) analysis procedure for GNSS-A positioning. The error ellipses clearly illustrate that the variance in array positions is large in the line-of-sight direction from an observation point to the array center. We translated the error ellipses to positioning accuracies using the standard deviation of travel time residuals when an array position is estimated using all pings. The positioning accuracy resulting from the translation corresponded to that obtained using array positions in a buoy observation. The DOP analysis results and their translation into positioning accuracies enabled a detailed assessment of the directional accuracy of GNSS-A positioning at an arbitrary observation position, which is important for realtime measurement of seafloor movement in the event of a huge earthquake.
\end{abstract}

Keywords: Seafloor geodesy, GNSS-Acoustic, Moored buoy, Dilution of Precision, Nankai Trough

\section{Introduction}

In subduction zones, large earthquakes occur in offshore areas and often generate disastrous tsunamis. Monitoring seafloor crustal movements in such areas during earthquakes is important for detecting tsunami generation and assessing the risks of subsequent ruptures. The GNSSAcoustic (GNSS-A) technique, pioneered by the Scripps Institution of Oceanography, can precisely measure the displacement of seafloor benchmarks by combining kinematic GNSS positioning with underwater acoustic ranging

\footnotetext{
* Correspondence: misae.imano.s1@dc.tohoku.ac.jp

${ }^{1}$ Graduate school of Science, Tohoku University, 6-3 Aza-aoba, Aramaki,

Aoba-ku, Sendai, Miyagi 980-8578, Japan

Full list of author information is available at the end of the article
}

(Spiess, 1985; Spiess et al. 1998). Since the 2000s, several research groups have been working on GNSS-A observation and have obtained numerous scientific results for the area around Japan, among others. For example, interseismic seafloor crustal movements have been found to constrain the slip deficit rate along the Nankai Trough (Tadokoro et al. 2012; Yokota et al. 2016; Yasuda et al. 2017), off the northeastern coast of Japan (Fujita et al. 2006; Sato et al. 2011a; Sato et al. 2013), and in the Okinawa Trough (Chen et al. 2017). Sato et al. (2011b) and Kido et al. (2011) detected coseismic displacements of the Tohoku earthquake (Mw 9.0) that reached magnitudes of more than $20 \mathrm{~m}$ near the Japan Trench. After the Tohoku earthquake, post-seismic deformations in and 
around the source area were also measured by Watanabe et al. (2014) and Tomita et al. (2017) and revealed the dominance of viscoelastic relaxation (Sun et al. 2014). However, it took approximately 20 days to obtain the first GNSS-A measurement after the Tohoku earthquake because most research vessels were occupied with rescue tasks. In addition, the typical frequency of a GNSS-A campaign survey during an interseismic period is only a few times per year.

To overcome these limitations, several attempts have been made to build a semi-permanent sea surface platform for continuous GNSS-A measurement and transmission of the data obtained to a land-based station. Chadwell et al. (2016) demonstrated the use of a Wave Glider that autonomously traveled more than 300 miles and carried out campaign GNSS-A observations at three sites in the Cascadia subduction zone. Around Japan, especially in the Nankai region, the sea current is too strong for a Wave Glider to be kept under control; a mooring system is needed instead. Moored Global Positioning System (GPS) buoys have been developed to monitor wave heights and tsunamis using real-time kinematic GPS positioning (Kato et al. 2000; 2011; Terada et al. 2015) or an on-site real-time precise point positioning (PPP, Zumberge et al. 1997) technique (Terada et al. 2013) along the Pacific coast of Japan. Kato et al. (2018) implemented a GNSS-A system for one of the moored buoys and began experimental measurements. Takahashi et al. (2014) developed a mooring system for seafloor crustal movement and tsunami monitoring and conducted a 3-month sea trial in 2013, $100 \mathrm{~km}$ from the Kii Peninsula, at a depth of $3000 \mathrm{~m}$. This mooring system was a prototype for our research. Improvements were made to the whole system and specifically to the GNSSA component that processes the data obtained and transmits the results automatically via satellite link. Subsequent sea trials were conducted for 5 months in 2014 (Takahashi et al. 2015) and for the full year of 2016 (Takahashi et al. 2017; Fukuda et al. 2017).

Kido et al. (2018) reported preliminary GNSS-A results from the latest sea trial mentioned above and discussed the difficulty of GNSS-A measurement on a widely drifting buoy. The sea trials were conducted as part of the Strategic Innovation Program (SIP), in which the target positioning accuracy was approximately $1 \mathrm{~m}$, which is the detectable level of fault movement of a disastrous M8-class earthquake. Although the typical repeatability of a campaign GNSS-A measurement with a controlled ship position is $5-10 \mathrm{~cm}$ (e.g., Kido et al. 2006; Tomita et al. 2015), a target accuracy of $1 \mathrm{~m}$ is a challenge with an uncontrollable buoy and with only a single ping or a few pings. This is because a slackly moored buoy moves around within a roughly circular area of nearly $4 \mathrm{~km}$ radius from the array center, in response to winds and currents. The drift of the buoy causes the following two problems in GNSS-A positioning. First, measurements far from the array center have a poor resolution (Kido, 2007). Second, measurements from different positions prevent the elimination of the effect of uncertainty in the array geometry (Kido et al. 2006). As reported by Imano et al. (2015), the array positions estimated using continuous observation data in our second trial (for 4 months in 2014) were clustered by approximately $4 \mathrm{~m}$, depending on the buoy position, because of the excessive uncertainty in the array geometry at that time. In contrast, Kido et al. (2018) achieved drastically improved accuracy (less than $1 \mathrm{~m}$ at $2 \sigma$ ) using the simultaneous geometry determination algorithm proposed by Honsho and Kido (2017) and accumulated ship-based three campaign data. However, Kido et al. (2018) mainly described the technical issues in GNSS-A systems on a buoy; they did not much discuss accuracy assessment of these systems. Furthermore, a latter portion of the time series of the data was unavailable due to instrument trouble.

In this paper, analysis procedures for GNSS-A data are first described, and a GNSS-A system for use with a moored buoy is then briefly introduced. Next, the series of observations used in this study, obtained from campaign surveys conducted using a research vessel and continuous measurements on the buoy, are described in detail. Array positioning results are presented for the full-time series, including the period for which data are missing in Kido et al. (2018). These latter results were obtained using data from a backup instrument. We introduce a new method for assessing GNSS-A positioning accuracy for our survey conditions and describe how the degradation of positioning accuracy depends on the geometry between an observation point and seafloor transponders (PXPs).

\section{Observations and methods}

\section{Observation system and site location}

A schematic illustration of our buoy system is shown in Fig. 1, focused on the GNSS-A part. The concept is to carry out continuous/on-demand observations, triggered by a command given via satellite link. The buoy was designed to be moored at deep ocean and in a strong current area because a huge earthquake $(\sim \mathrm{Mw} 8)$ along the Nankai Trough is expected to occur in such a region. To resist the strong current, with a maximum speed of approximately 5.5 knots, we adopted a slack mooring technique (Ishihara et al. 2012) using a cable $4700 \mathrm{~m}$ long, i.e., much longer than the depth $(3000 \mathrm{~m})$. The slack ratio, which is the ratio of the total length of the cable to its depth, is 1.57 in this system, which results in a drifting rage of up to $4 \mathrm{~km}$. The buoy system is described in detail by Takahashi et al. (2017), and the GNSS-A component is described in detail by Kido et al. (2018). 


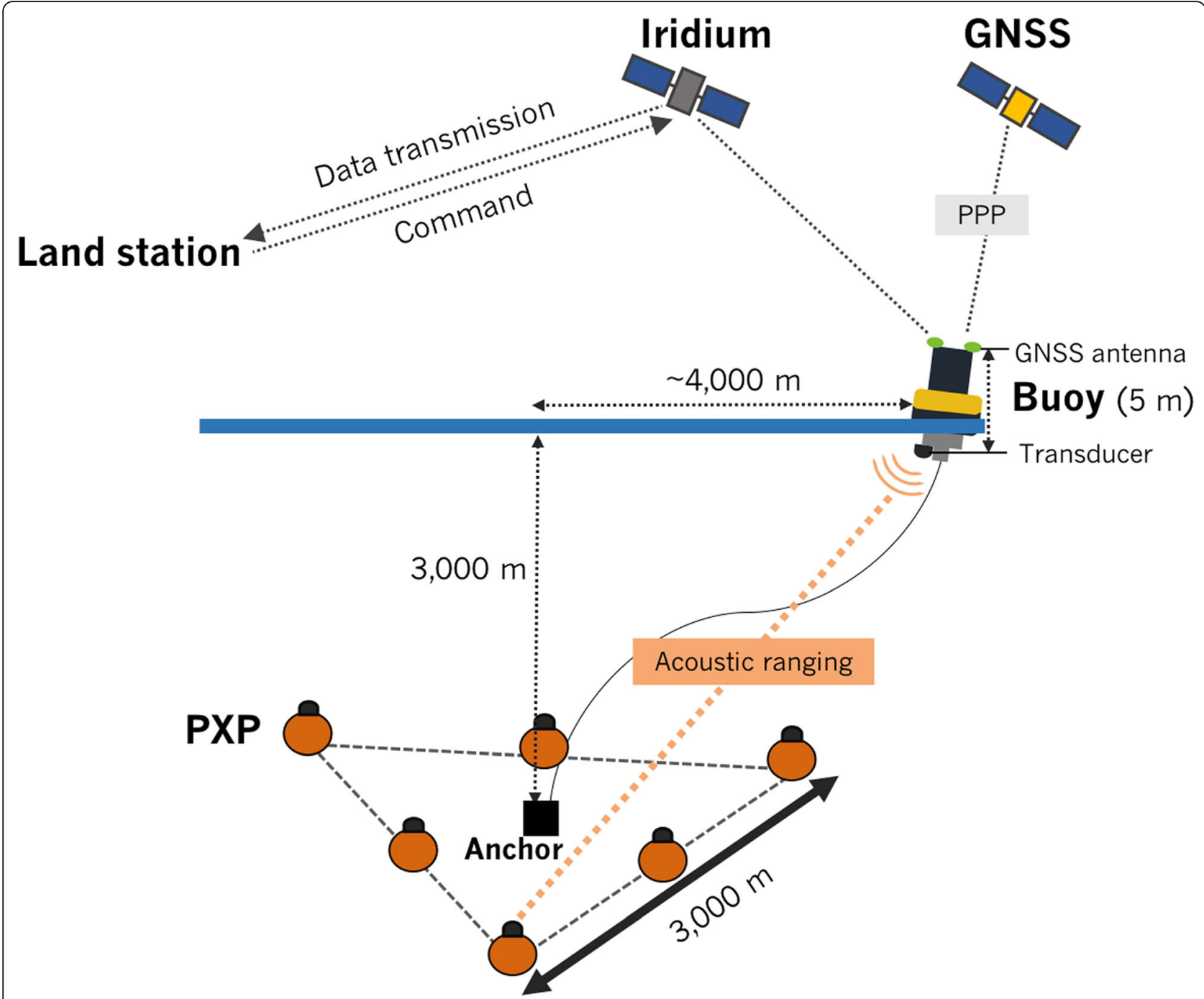

Fig. 1 Schematic illustration of GNSS-A seafloor positioning using a slackly moored buoy system. The buoy is moored with an anchor (approximately 6 tons) using a sufficiently longer rope $(4700 \mathrm{~m})$ than the depth $(3000 \mathrm{~m})$ near the center of the PXP array, which consists of six PXPs aligned in a triangle. A sequence of GNSS-A observations is carried out automatically at preset intervals (11 shots/week) or on demand from a land-based station. At the end of a measurement sequence, the data are transmitted to the land-based station via Iridium satellite communication

Six PXPs for GNSS-A were installed in 2012 on a small terrace on the landward slope along the Nankai Trough, at a depth of approximately $3000 \mathrm{~m}$ and a distance of $100 \mathrm{~km}$ from the Kii Peninsula (Fig. 2a). Although the minimum required number of PXPs is three, we employed six PXPs to greatly improve the positioning accuracy achieved, as discussed later, and to help in evaluating possible spatial sound speed variation in a campaign survey due to the Kuroshio current. The area is known as the Kuroshio region, and the current speed in this region reaches 5.5 knots, which is suitable for torture testing. From a scientific point of view, the site is close to the trough axis and is expected to be sensitive to whether ruptures reach the axis, as with the 2011 Tohoku earthquake, and to possible mega splay faults.

\section{GNSS-A measurement and analysis}

A GNSS-A observation system consists of a sea surface platform that is equipped with GNSS antennas, a gyro sensor, and an acoustic transducer, together with three or more PXPs aligned in a triangle or a square on the seafloor. The basic steps in GNSS-A data processing are as follows: (1) kinematic GNSS analysis for positioning of the antenna on the surface platform; (2) translation of the GNSS antenna position into a transducer position at the time of transmission and reception of acoustic signals based on the platform attitude and pre-measured antenna-transducer configuration; (3) acoustic signal processing for picking round-trip travel times; (4) calculation of a sound speed profile from the sea surface to the 


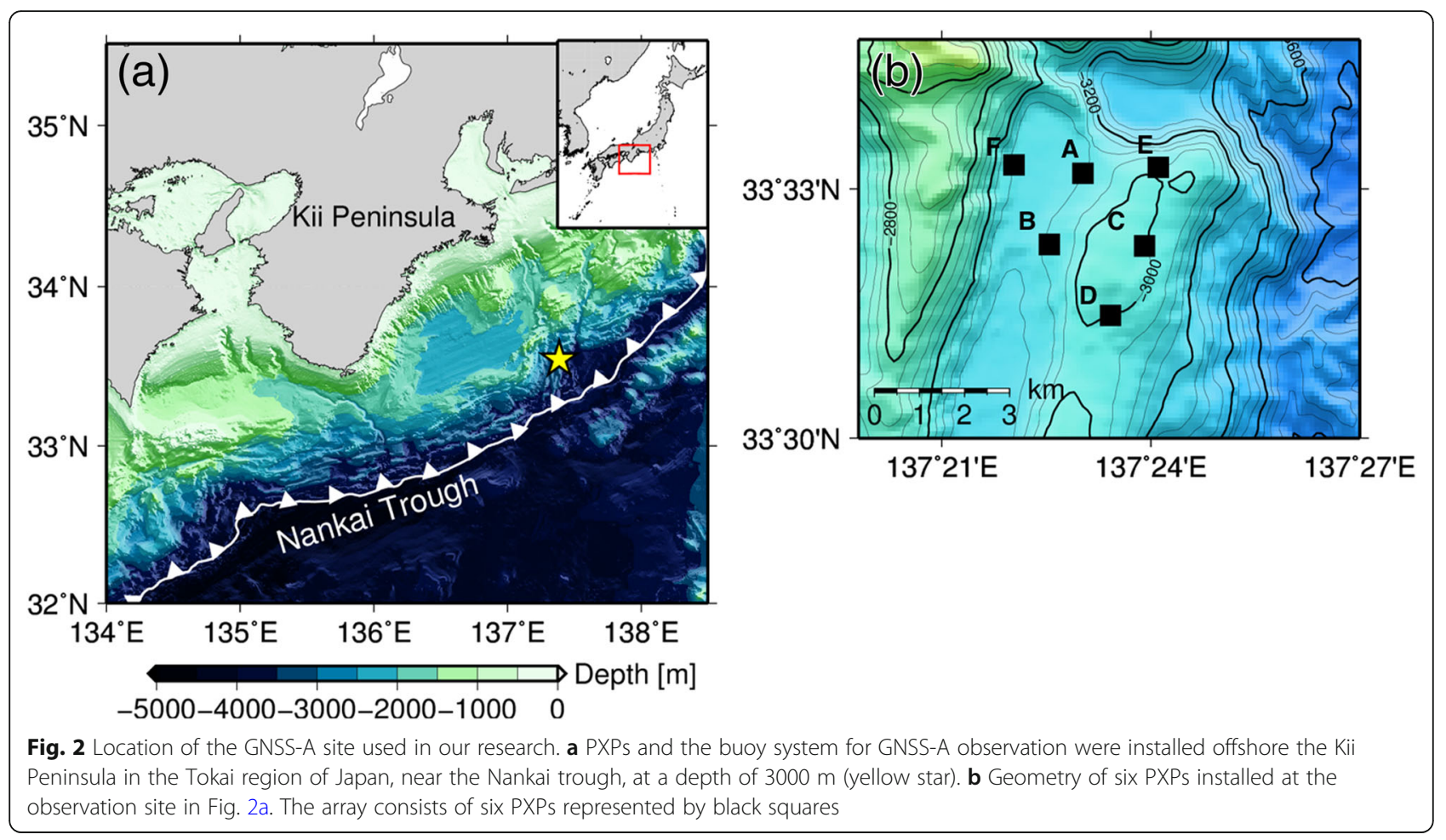

seafloor based on expendable bathythermograph (XBT)/ conductivity, temperature, and depth (CTD)/expendable CTD (XCTD) measurement and extrapolation; and (5) inversion of all of these data to determine the positions of the transponders and the temporal sound speed variation.

We adopted a two-step approach to GNSS-A positioning consisting of two survey types proposed by the Scripps Institution of Oceanography (Spiess et al. 1985). The first type is a "moving survey" in which a surface platform is moved around and across the transponder array, gathering round-trip times with various incident angles and directions. The positions of the individual transponders, and hence the geometry of the array and its initial position, are determined through this type of survey. The second type of survey is a "point survey" in which round-trip times are measured at a fixed point (typically just above the array center). The array is assumed to be rigid, with the geometry determined from a moving survey, and the horizontal displacement of the array with respect to the initial position is estimated. In most cases, the vertical displacement is not determined because it is in trade-off relation with sound speed change. In the analysis, the sound speed change is represented by the nadir total delay (NTD), which is the effective delay in travel time normalized with respect to the vertical path. Assuming that a sound speed structure is laterally stratified, we determine the horizontal array position and temporal change in
NTD for each ping by minimizing the difference between observed and synthetic travel times. In the case of an observed position not being fixed, as in the case of a moored buoy, the accuracy of the initial determination of the array geometry is crucial (Imano et al. 2017). Therefore, we employ a method proposed by Honsho and Kido (2017) in which the data obtained from multiple moving surveys are processed simultaneously to determine an array geometry and its initial position reliably, as well as the time-varying NTD, represented by a finite number of bi-cubic B-spline functions. We then estimate the horizontal array position in terms of the east-west (EW) and north-south (NS) components $(x, y)$ and the NTD $d t$ for each ping as three unknowns, $\boldsymbol{q}=(x, y, d t)$, according to the method used by Kido et al. (2006; 2008). We define a residual $d T_{k}$ between synthetic and observed round-trip travel times, normalized with respect to the incidental angle $\theta_{k}$ for the $k^{\text {th }}$ PXP, as follows:

$$
d T_{k}=\left[T_{k}-f\left(\boldsymbol{q} ; \boldsymbol{p}_{k}, \boldsymbol{r}, V_{0}(z)\right)\right] \cos \theta_{k} \quad(k=1,2, \ldots, K)
$$

where $T_{k}$ is a round-trip travel time between a surface transducer position $r$ and the $k^{\text {th }}$ seafloor PXP position $\boldsymbol{p}_{k}$ and $f$ is a function that yields a synthetic travel time by ray-tracing between $\boldsymbol{r}$ and $\boldsymbol{p}_{k}$, assuming that the sound speed structure is horizontally stratified, using a reference sound speed profile $V_{0}(z)$. The observation 
equation for array positioning, linearized around a successive solution, is written as follows:

$$
d T_{k}=\left(\frac{\partial f_{k}}{\partial x} \delta x+\frac{\partial f_{k}}{\partial y} \delta y\right) \cos \theta_{k}+\delta d t(k=1,2, \ldots, K) .
$$

We can calculate horizontal array positions relative to the pre-determined array position by minimizing $\sum_{k=1}^{K} d T_{k}^{2}$. Although a minimum of three travel times are required to solve for the unknowns for each ping, we determine the array position only when all six PXPs respond simultaneously, to minimize the effect of uncertainty in the pre-determined array geometry. The reference sound speed profile $V_{0}(z)$ is based on XBT/XCTD measurements, using the Munk profile (Munk, 1974) for the deeper portion. Details of the observations and data are provided in the following section.

\section{Determination of array geometry}

To determine an array geometry for our study site, we carried out three campaign GNSS-A observations using a research vessel, in June 2014, June 2016, and December 2016, for the purpose of individual PXP positioning. Figure 3 shows the data distributions of all the campaign observations. The three campaigns obtained 4558, 3746, and 10535 travel times in total. Details of each campaign are shown in Additional file 1: Figure S1. Travel time data during one of the campaigns are shown in Additional file 1: Figure S2 as an example.

Applying the simultaneous estimation algorithm for multiple campaigns proposed by Honsho and Kido (2017) to all of the ship-based campaign data collected as described above, we successfully determined individual PXP positions (i.e., the array geometry and initial array position). In the analysis, sound speed variation (NTD) was represented by cubic spline functions with a 250-s interval, which adequately captured short-term fluctuations in the ocean. The positions obtained are listed in Table 1. As shown in Additional file 1: Figure S3, the observed NTD variations (colored dots) were synchronized among the PXPs and well represented by the modeled NTD variations (black lines); one standard deviation of the observed NTDs from the model was generally $0.07 \mathrm{~ms}$ for the three campaigns, which was slightly larger than but comparable to the values presented by Honsho and Kido (2017). Therefore, we consider that the time variation of sound speed and the PXP positions were estimated as accurately as Honsho and Kido (2017). This indicates that the PXP positions were determined precisely. The estimation errors associated with the PXP positions were approximately $1 \mathrm{~cm}$ and approximately $1.6 \mathrm{~cm}$ for the horizontal and vertical components, respectively. The estimation errors are likely to be underestimated because possible modeling errors are not taken into account (Honsho and Kido, 2017). However, we confirmed that uncertainty associated with the array geometry does not have a great effect on the array positions, as described in the following section.

\section{Array positioning for buoy observation}

In continuous observation using the moored buoy system, GNSS-A measurements were carried out once a week from December 2015 to December 2016. A set of measurements consisted of 11 successive acoustic ranging at 65-s intervals. In addition to the regular measurements, on-demand measurements were also performed. Fifty-three regular measurements and 55 on-demand measurements were conducted. Most of the on-demand measurements were conducted when the buoy was inside the array (Additional file 1: Figure S4).

The buoy was equipped with two sets of GNSS systems so that each could serve as a backup for the other. One was an MB-One receiver module (Trimble) with a GNSS antenna (ANT30001R, NAVCOM). The other was a sigma-Q receiver (JAVAD) with four Gr-Ant3
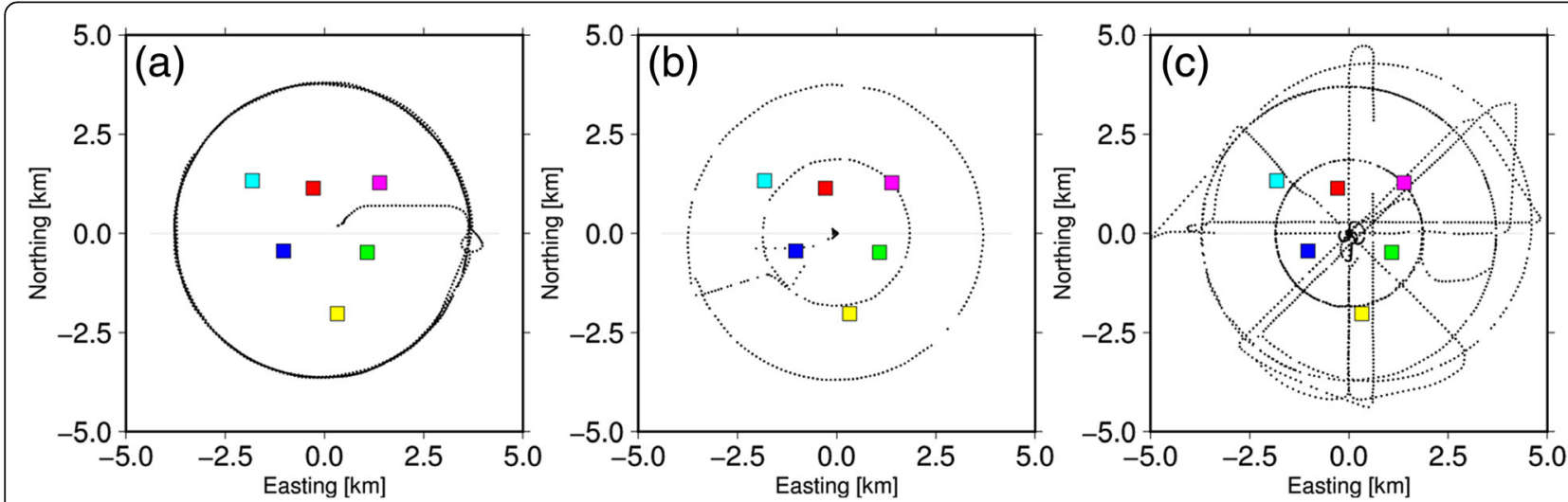

Fig. 3 Data distribution of three ship-based observations. The black dots represent the observation position in a moving or point survey. The colored squares are the six PXPs, which correspond to the residuals in the determination of the array geometry (Additional file 1: Figure S3) 
Table 1 Results of individual PXP positioning

\begin{tabular}{|c|c|c|c|c|c|c|}
\hline \multicolumn{7}{|c|}{ PXP positions } \\
\hline \multirow[b]{2}{*}{ PXP } & \multicolumn{3}{|c|}{ Position and height (m) } & \multicolumn{3}{|c|}{ Estimation error (m) } \\
\hline & EW & NS & UD & EW & NS & UD \\
\hline A & $136^{\circ} 42.10110^{\prime} \mathrm{E}$ & $33^{\circ} 35.56253^{\prime} \mathrm{N}$ & -3055.682 & 0.009 & 0.010 & 0.016 \\
\hline B & $136^{\circ} 41.61887^{\prime} \mathrm{E}$ & $33^{\circ} 34.70780^{\prime} \mathrm{N}$ & -3043.047 & 0.010 & 0.009 & 0.017 \\
\hline C & $136^{\circ} 42.98246^{\prime} \mathrm{E}$ & $33^{\circ} 34.68963^{\prime} \mathrm{N}$ & -2947.230 & 0.010 & 0.009 & 0.017 \\
\hline D & $136^{\circ} 42.49562^{\prime} \mathrm{E}$ & $33^{\circ} 33.85166^{\prime} \mathrm{N}$ & -2964.283 & 0.009 & 0.013 & 0.016 \\
\hline $\mathrm{E}$ & $136^{\circ} 43.18333^{\prime} \mathrm{E}$ & $33^{\circ} 35.63492^{\prime} \mathrm{N}$ & -2981.481 & 0.011 & 0.010 & 0.016 \\
\hline 1 & $136^{\circ} 41.11050^{\prime} \mathrm{E}$ & $33^{\circ} 35.66362^{\prime} \mathrm{N}$ & -3057.239 & 0.013 & 0.011 & 0.015 \\
\hline
\end{tabular}

antennas that also measured attitude at $2.5 \mathrm{~Hz}$ using a four-antenna array. We used the data from the MB-One system primarily for the GNSS-A analysis. The MB-One internally processed the data, performing a PPP-based analysis, at $10 \mathrm{~Hz}$ using Trimble CenterPointRTX service during each GNSS-A measurement. The nominal accuracy of the CenterPointRTX is approximately $4 \mathrm{~cm}$ in the horizontal direction. Carrier-phase data from GPS/GLONASS satellites were recorded in a logger at a 2-Hz sampling rate, not only during GNSS-A measurement but also throughout the mooring observation period (December 2015-December 2016). Attitude data from the JAVAD system were missing after 17 October 2015 because of a hardware problem. Additional file 1: Figure S5a shows all of the attitude data collected until October 17, and Additional file 1: Figure S5b shows a selected set of measurements obtained over a short time interval (approximately $14 \mathrm{~min}$ ). There are two peaks at $3-4 \mathrm{~s}$ in pitch and roll and 30-50 s in a heading, pitch, and roll (Fig. 5c). The former corresponds to the characteristic period of pitching and rolling of the moored buoy. The latter originates in the interaction of long-period ocean swell and the tense tether line of the buoy. For backup of the GNSS gyro described above, a MEMS gyro sensor (MTi-G, Xsens) was mounted to measure angular velocity and linear acceleration at a $20-\mathrm{Hz}$ sampling rate. We estimated the attitude of the buoy from the Xsens data, using the method proposed by Honsho et al. (2015).

For the regular and on-demand acoustic measurements, the total number of shots amounted to 1188 $(=(53+55) \times 11)$ pings in total. In the real-time processing, travel times were selected automatically onboard by cross-correlating the transmitted and recorded acoustic waveforms and selecting a peak of the correlogram for each PXP, as described by Kido et al. (2018). Although pseudo peaks produced by sea surface multipaths were automatically removed, the algorithm cannot remove double multipaths (reflection at both transmission and reception). Therefore, we manually reselected travel times for such a case after retrieval of the buoy. After the reselection, we selected $527 \times 6=3162$ travel times for array positioning up to 19 December 2016. The travel times selected exceeded a noise threshold of a correlogram peak (the value of the cross-correlation coefficient, 0.4) and instances when all six PXPs simultaneously responded to a ping.

Applying the method described by Kido et al. (2006), which is represented by Eqs. (1) and (2), to the mooring observation data obtained as described above, we estimated horizontal array positions relative to the array geometry determined as described in the previous section. We usually measure the sound speed profile at each campaign survey. However, the figures of the profiles do not change drastically, and bending of acoustic ray paths can be regarded unchanged. Only averaged temporal change through the water column is estimated as the NTD, which is sufficient to correct travel times. Buoy-based observation inherently has no chance to make a XBT casting, and therefore, we used a reference sound speed profile obtained in campaign 2 (Additional file 1: Figure S1) for the buoy-based survey, which can be validated for the reason described above.

\section{Results \\ Array positions}

Figure 4 shows a map of buoy positions and a map view and time series of the estimated array positions for each ping. The track during the mooring period is indicated by gray lines in Fig. 4a, and the positions of regular and on-demand measurements are indicated by solid circles. Most of the time, the moored buoy was on the circumference of a circle with a radius of approximately $4 \mathrm{~km}$ whose center was at the anchor point. Note that the anchor point is approximately $500 \mathrm{~m}$ from the array center. Conditions permitting GNSS-A measurements inside the array occurred in January, March, and April of 2016. In addition, on-demand measurements had to be conducted concurrently with the ship-based campaign survey in June and December of 2016. The timing of these intensive on-demand measurements is indicated by gray arrows in Additional file 1: Figure S4.

In Fig. $4 \mathrm{~b}-\mathrm{d}$, array positions determined when the buoy was inside the array are plotted in red, and those determined when the buoy was outside the array are plotted in blue, the latter corresponding to the ping positions shown in Fig. 4a. One hundred and four ping positions were inside, and 423 were outside. We expressed the accuracy of array positioning by the standard deviation $(2 \sigma)$ of the estimated array positions from the initial position, ignoring the steady-state displacement near this site (approximately $4 \mathrm{~cm} /$ year, according to Yasuda et al. 2017) because it is quite small relative to the target accuracy. The positioning accuracies in the horizontal direction inside and outside the array using the buoy system were $46 \mathrm{~cm}$ and $97 \mathrm{~m}$, respectively (Table 2). 


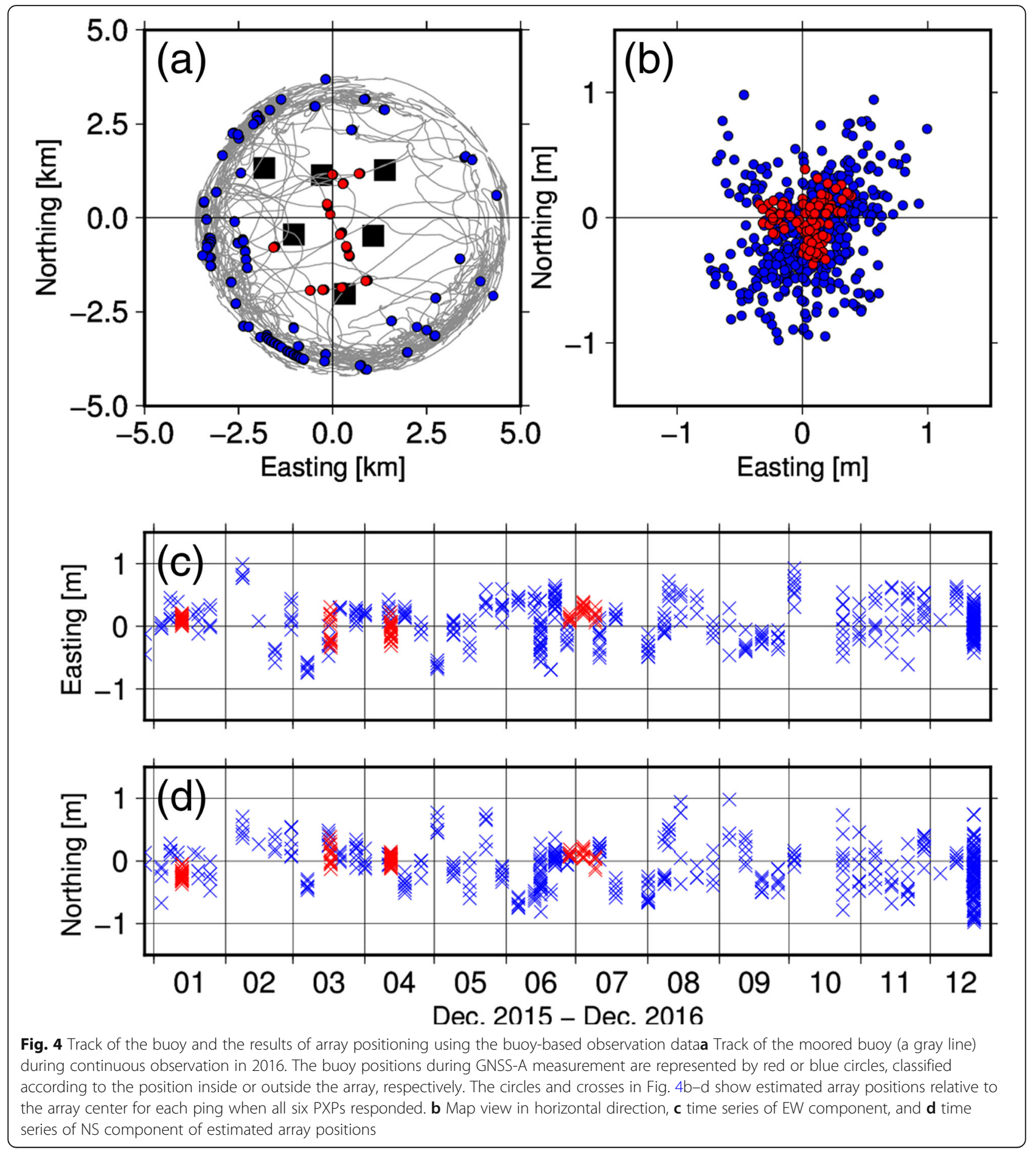

Comparison with array positions using ship-based observation data

There expected a couple of factors that possibly degrade the accuracy of the buoy-based survey than ship-based survey. For example, the buoy swings much faster than a ship; the buoy survey employed real-time kinematic PPP analysis while the ship-based survey usually employs differential analysis to the onshore station by post-processing. To compare the accuracies of buoy and ship-based observations, we also estimated array positions using data collected in the three campaigns, as mentioned previously in the section on individual PXP positioning. To compare the accuracies of the two types of observations, we used ping data obtained only when all six PXPs responded, whereas all of the 
Table 2 Accuracy of array positioning

\begin{tabular}{|c|c|c|c|c|c|c|}
\hline \multirow{2}{*}{$\begin{array}{l}\text { Surface } \\
\text { platform }\end{array}$} & \multicolumn{3}{|c|}{ Inside (cm) } & \multicolumn{3}{|c|}{ Outside (cm) } \\
\hline & EW & NS & Horizontal & EW & NS & Horizontal \\
\hline Moored buoy & 33 & 33 & 46 & 65 & 73 & 97 \\
\hline Research vessel & 23 & 30 & 39 & 109 & 114 & 158 \\
\hline $\begin{array}{l}\text { Research vessel } \\
\text { (moving survey) }\end{array}$ & 52 & 56 & 76 & 109 & 114 & 158 \\
\hline $\begin{array}{l}\text { Research vessel } \\
\text { (point survey) }\end{array}$ & 16 & 25 & 30 & & & \\
\hline
\end{tabular}

ping data were used for individual PXP positioning. Using this approach, 1497 and 361 array positions were estimated using the campaign data collected inside and outside the array, respectively. The positioning accuracies achieved inside and outside the array using a research vessel were approximately $40 \mathrm{~cm}$ and approximately $1.5 \mathrm{~m}$, respectively (Fig. 5 and Table 2). These results indicate that the positioning accuracy achieved using the buoy system was almost the same as that achieved using a research vessel. Figure 6 shows the deviations in the estimated array position relative to the initial position, using error bars for individual observation points. The lengths and orientation of the error bars correspond to the deviations, on the scale indicated in the panel. We can clearly see that the positioning accuracy is worse outside the array for both the buoy data and ship data. We also found that the orientations of the error bars were roughly consistent with the line-of-

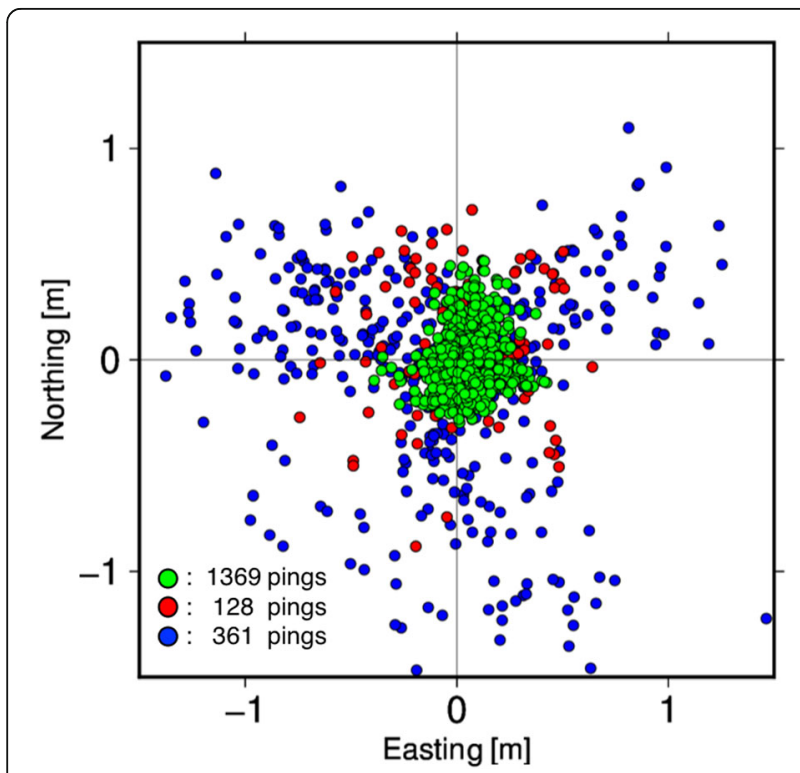

Fig. 5 Estimated array positions using ship-based campaign observation data.The blue circles indicate results obtained when observation positions are outside the array, the red circles indicate results obtained when observation positions are inside the array, and the green circles indicate results obtained from a point survey at the center of the array sight directions from observation positions to the array center. This can be interpreted to mean that the trade-off between array position estimation accuracy and sound speed change estimation accuracy is great in the line-of-sight direction from an observation position. Imano et al. (2015) showed that uncertainty associated with a pre-determined array geometry produces an uneven systematic error (up to $5 \mathrm{~m}$ ) in the array positioning at a specific observation point. However, no such systematic pattern is evident in Fig. 6. This indicates that the uncertainty in the array geometry was sufficiently small. The degradation of array positioning accuracy seems to be simply caused by the positional relation between an observation point and the PXP positions, as noted by Kido et al. (2018). We discuss this issue in detail in the following section.

\section{Discussion}

\section{Definition of DOP of GNSS-A positioning}

Kido (2007) quantitatively evaluated the degree of propagation of data error (e.g., error in sea surface platform position or travel times) as a function of observation positions, using a "condition number" defined using a Jacobian of a linearized observation equation. This approach was also employed by Kido et al. (2018) in analyzing buoy data. However, this approach only explains the degradation of the horizontal component of array positioning. To evaluate the degradation separately in the EW and NS directions, we employed the dilution-of-precision method (DOP, Langley, 1999) which is traditionally used to examine GNSS positioning accuracy. Recently, it has also been applied to underwater positioning (e.g., Taraldsen et al. 2011).

We applied DOP to GNSS-A positioning to evaluate the accuracy of unknown parameters that depend on the geometry between an observation point and PXP positions, based on Langley (1999). Equation (2) can be rewritten with a non-dimensionalized Jacobian as follows:

$$
\delta \mathbf{T}=\hat{\mathbf{A}} \delta \hat{\mathbf{q}}
$$

where

$$
\begin{aligned}
& d T_{k}=\left[T_{k}-f\left(\boldsymbol{q} ; \boldsymbol{p}_{k}, \boldsymbol{r}, V_{0}(z)\right)\right] \cos \theta_{k} \quad(k=1,2, \ldots, K) \\
& \widehat{A_{k}}=\left[\begin{array}{lll}
V_{0} \frac{\partial f_{k}}{\partial x} \cos \theta_{k} & V_{0} \frac{\partial f_{k}}{\partial y} \cos \theta_{k} & 1
\end{array}\right] \quad(k=1,2, \ldots, K) \\
& \delta \hat{\mathbf{q}}=\left[\begin{array}{lll}
\frac{\delta x}{V_{0}} & \frac{\delta y}{V_{0}} & \delta d t
\end{array}\right]^{\mathrm{T}}
\end{aligned}
$$

and $V_{0}$ is an arbitrary reference sound speed employed for non-dimensionalization. We obtained the partial 

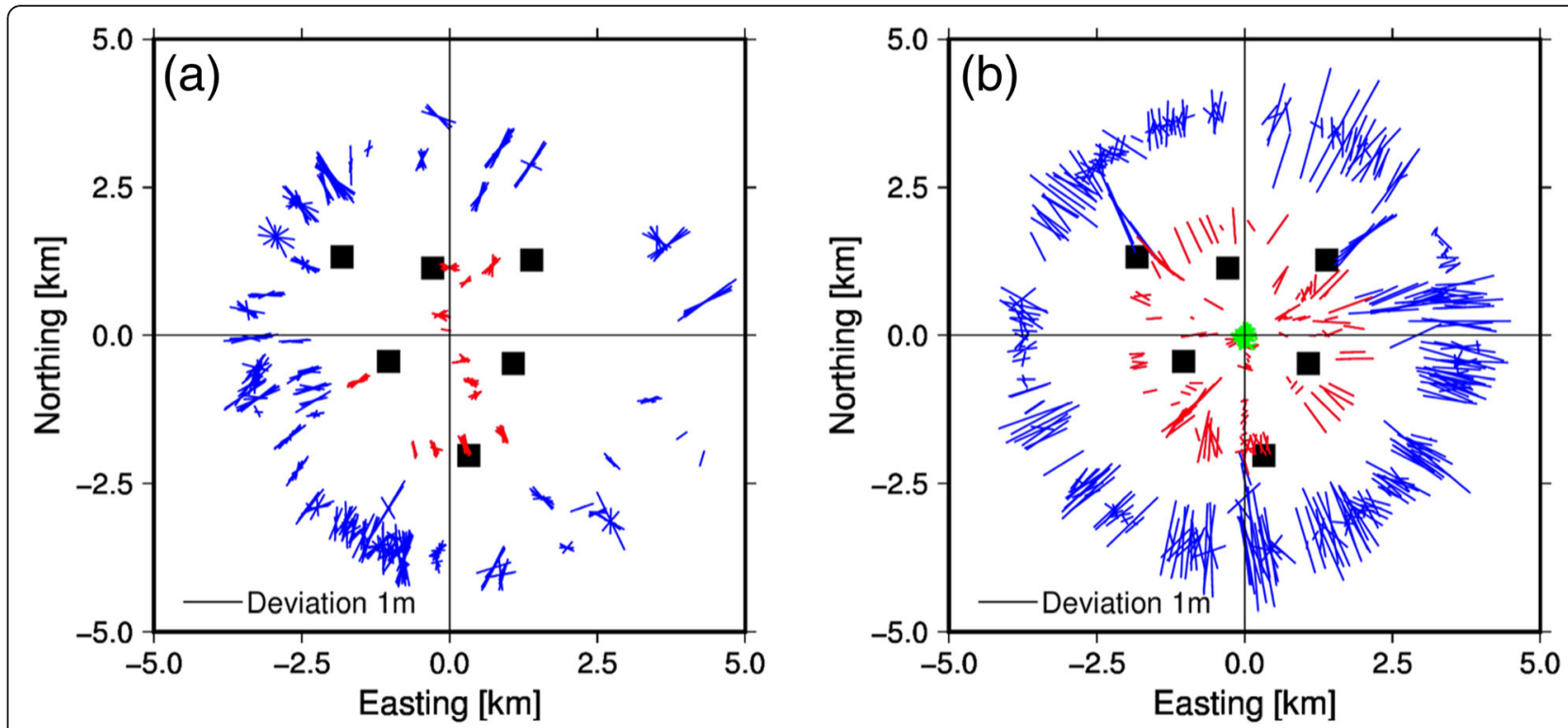

Fig. 6 Array positions projected as bars as a function of observation position.A bar represents the horizontal deviation of array positions ( $\sqrt{\delta x^{2}+\delta y^{2}}$ ) based on (a) buoy-based observation and (b) ship-based observation. The black bar located at the bottom left in each panel indicates a deviation scale of $1 \mathrm{~m}$ deviation. The blue bars correspond to observation positions outside the array, and the red bars correspond to observation positions inside the array. The orientations of the bars indicate the orientations of array positions relative to the initial position

derivative of $f_{k}$ with respect to $x$ and $y$ using the approach presented by Honsho and Kido (2017). The covariance of $\delta \hat{\mathbf{q}}$ with an estimation error $\sigma$ is as follows:

$$
\mathbf{C}_{\boldsymbol{\delta} \mathbf{q}}=\left(\hat{\mathbf{A}}^{\mathbf{T}} \hat{\mathbf{A}}\right)^{-1} \sigma^{2}
$$

where

$$
\left(\hat{\mathbf{A}}^{\mathbf{T}} \hat{\mathbf{A}}\right)^{-1}=\left[\begin{array}{ccc}
D_{x x} & D_{x y} & D_{x d t} \\
D_{y x} & D_{y y} & D_{y d t} \\
D_{d t x} & D_{d t y} & D_{d t d t}
\end{array}\right]
$$

and $D_{x x}, D_{y y}$, and $D_{d t d t}$ are scaling factors of the degradation in estimation of the EW, NS, and time delay components. The degradations in array positioning in the horizontal, EW, and NS components are defined as follows (Kaplan and Hegarty, 2006):

$$
\begin{aligned}
& \mathrm{HDOP}=\sqrt{D_{x x}+D_{y y}} \\
& \mathrm{EDOP}=\sqrt{D_{x x}}, \text { and } \\
& \mathrm{NDOP}=\sqrt{D_{y y}}
\end{aligned}
$$

We computed EDOP, NDOP, and HDOP as a function of an observation point using our array geometry, shown in Additional file 1: Figure S6. A large DOP value corresponds to degraded positioning accuracy, indicating difficulty in distinguishing each component of an array position component from the delay due to the temporal variation of sound speed. We also examined the case of three PXPs (Additional file 1: Figure S7), which is the minimum number required for GNSS-A positioning. Because the case of three PXPs has no redundancy, a mathematically indefinite position (HDOP is singular) appears outside the array for horizontal positioning. In this region, there is a full tradeoff between the array position and sound speed variation. This underscores the importance of a redundant PXP layout, especially for observations from uncontrollable moored buoys.

Additional file 1: Figure S8 shows that the covariances $\left(D_{x y}\right.$ and $\left.D_{y x}\right)$ in Eq. (8) are large through the entire drifting range of the buoy. Therefore, it is not appropriate to assess the degradation of positioning accuracy using only the variances $\left(D_{x x}\right.$ and $\left.D_{y y}\right)$ shown in the definitions of DOP in Eqs. (9) to (10). To take the covariances into account, we calculated error ellipses at each observation position by diagonalization of a $2 \times 2$ matrix whose elements are $D_{x x}$, $D_{x y}$, and $D_{y y}$ in Eq. (8). We defined a matrix of diagonalized DOP D as follows:

$$
\mathbf{D}=\left[\begin{array}{cc}
\lambda_{1}^{2} & 0 \\
0 & \lambda_{2}^{2}
\end{array}\right]\left(\lambda_{1}>\lambda_{2}\right)
$$

where $\lambda_{1}$ and $\lambda_{2}$ are the lengths of the major and minor axes of the error ellipses, respectively. 
A map view of the error ellipses using the diagonalized DOP shown in Fig.7 has two characteristics: (1) the error ellipses outside the array are larger than those inside the array, and (2) the error ellipses are headed in the direction from an observation position to the array center. This is consistent with the characteristics of the estimated array positions shown in Fig. 6, indicating that the observed array position errors mainly arise from propagated random data errors according to the positional relationship as the DOP predicts.

\section{Synthetic testing}

In the previous section, we described how we compared the deviation bars of actual observed data (Fig. 6) with error ellipses by means of an analytical approach using the diagonalized DOP (Fig. 7). The DOP-based ellipses directly evaluate the propagation of errors in travel time that follow the Gaussian distribution. On the contrary, actual observation should be affected by nonGaussian errors: discrete travel time misreading and vertical GNSS uncertainty. Therefore, we carried out intensive numerical synthetic tests to examine the behavior of such non-Gaussian errors. We prepared observation positions at $100-\mathrm{m}$ intervals on the sea surface within a region approximately $5 \mathrm{~km}$ square, centered at the array center $(101 \times 101$ grids $)$, and travel times were calculated between the grid points and each of the six PXPs, the actual geometries of which are listed in Table 1. Random data error was

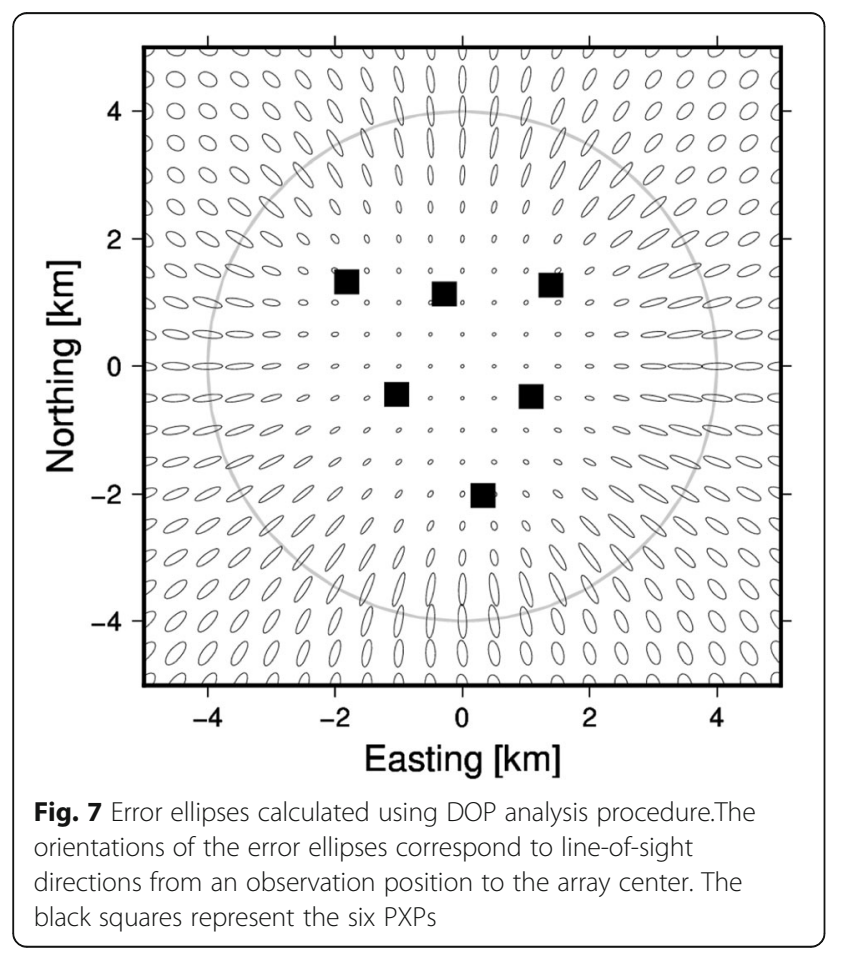

taken into account, as well as error in selecting the sidelobe in the correlogram $(-0.1,0$, and $+0.1 \mathrm{~ms}$ in even probabilities) for travel time and vertical GNSS uncertainty $(0.1 \mathrm{~m}$ in the Gaussian at $2 \sigma)$ for the antenna or transducer position. The horizontal GNSS error does not need to be examined because it propagates directly into the array positions without amplification (Kido et al. 2006). Synthetic testing was performed 1000 times for each observation position, resulting in different errors in each test. We calculated error ellipses by principal component analysis using the array positions obtained from synthetic testing for comparison with the error ellipses calculated using the analytical approach described in the previous section. The obtained error ellipses are in good agreement with those from diagonalized DOP-based analysis (Fig. 8), indicating realistic non-Gaussian errors practically behave as the synthetic Gaussian errors. This supports the use of diagonalized DOP for assessment of the accuracy of GNSS-A positioning.

\section{Translation of DOP into positioning accuracy}

The use of DOP permits the assessment of positiondependent accuracy and even the directional nature of the accuracy achieved for a single ranging in buoy-based GNSS-A measurement. However, DOP quantities indicate relative accuracy or directional ratios and cannot directly characterize absolute accuracy. By numerically comparing the DOP-based accuracy results with the synthetic test results obtained as described in the previous section, the DOP quantities can be translated into absolute accuracies.

DOP and positioning accuracy are linearly related for each component, with a scaling factor $\sigma$ (Kaplan and Hegarty, 2006). The horizontal positioning accuracy $(1 \sigma)$ is defined using the diagonalized DOP $\mathbf{D}$ as follows:

$$
\sigma_{\mathrm{H}}=\sqrt{\lambda_{1}^{2}+\lambda_{2}^{2}} \times \sigma \times V_{0} .
$$

Once $\sigma$ is given, the directional accuracies $\sigma_{1}$ and $\sigma_{2}$ for the major and the minor components, respectively, are calculated in the same manner as is $\sigma_{\mathrm{H}}$ :

$$
\sigma_{i}=\lambda_{i} \times \sigma \times V_{0} \quad(i=1,2) .
$$

We estimated the scaling factor $\sigma$ from the buoy observation data (527 pings). This scaling factor is an estimation error common to GNSS-A positioning for all pings. The scaling factor is a common residual multiplied by a sound speed $V_{0}$ for the purpose of nondimensionalization in Eqs. (5) and (6) when a horizontal array position is estimated simultaneously by minimizing $\sum_{i=1}^{I} \sum_{k=1}^{K} d T_{k, i}^{2}$. We set $V_{0}$ to a typical sound speed, 


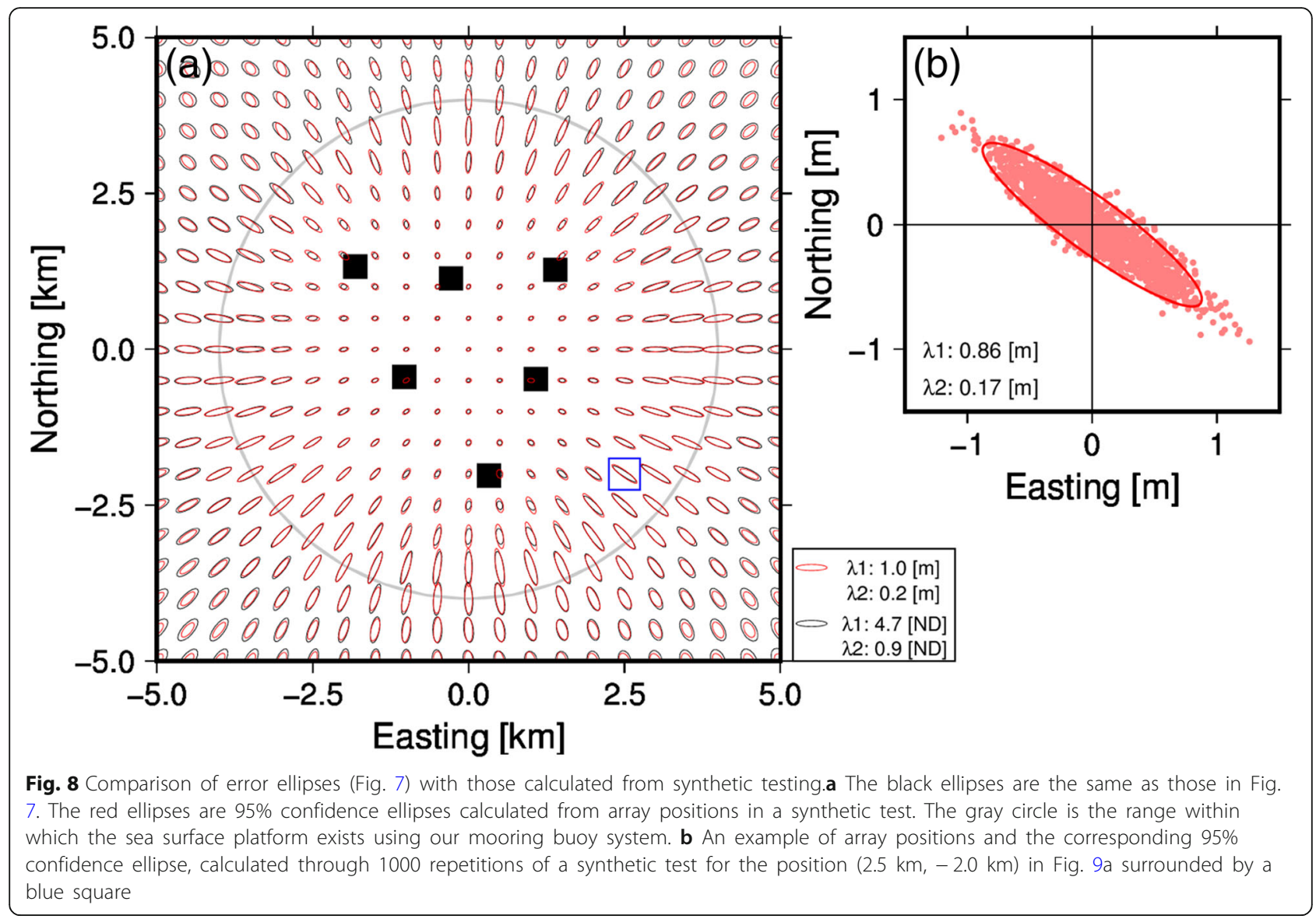

$1500 \mathrm{~m} / \mathrm{s}$. We then obtained the standard deviation of travel time residuals, $0.098 \mathrm{~ms}$. Figure 9 shows that the horizontal positioning accuracy $(2 \sigma)$ calculated using Eq. (13) almost corresponds to the one calculated using array positions from buoy-based observations. The latter is larger than the former when HDOP is less than 2 . This is probably because of errors in the estimated array positions resulting from model errors, such as horizontal variation in the sound speed structure. On the other hand, the latter is smaller than the former when HDOP is approximately 5 . These accuracies were calculated using array positions obtained from intensive observation during campaign 3 . Therefore, there is a possibility that the data or model errors were smaller during this observation period than during other observations. However, we have demonstrated that the translation described previously provides an estimate of the positioning accuracy using only an array geometry and an observation point, once a value for $\sigma$ is calculated using all pings.

As described above, we can easily translate diagonalized DOP into positioning accuracy. The advantage becomes especially obvious for separate directional estimates of $\sigma_{1}$ and $\sigma_{2}$. It is clear that the positioning accuracy of GNSS-A measurements should be determined considering directional characteristics, depending on the observation point. Although GNSS-A measurement is performed under severe conditions, such as outside the array, we can derive considerable information concerning seafloor displacement from estimated array positions.

\section{Conclusions}

We have assessed the horizontal positioning accuracy of GNSS-A observations for a slackly moored buoy near the Nankai Trough, using data obtained from regular and on-demand measurements over the course of a year. The data obtained from three ship-based observation campaigns were used to determine the array geometry precisely and were also analyzed for comparison of the array positions determined to those determined using the buoy observation data. Because the buoy drifted a significant distance from the array center, the accuracies were classified into two categories, based on whether the observation position was inside or outside the PXP array. The positioning accuracies obtained for a single measurement using a buoy and a research vessel inside versus outside of the array were 0.46 versus $0.97 \mathrm{~m}$ and 


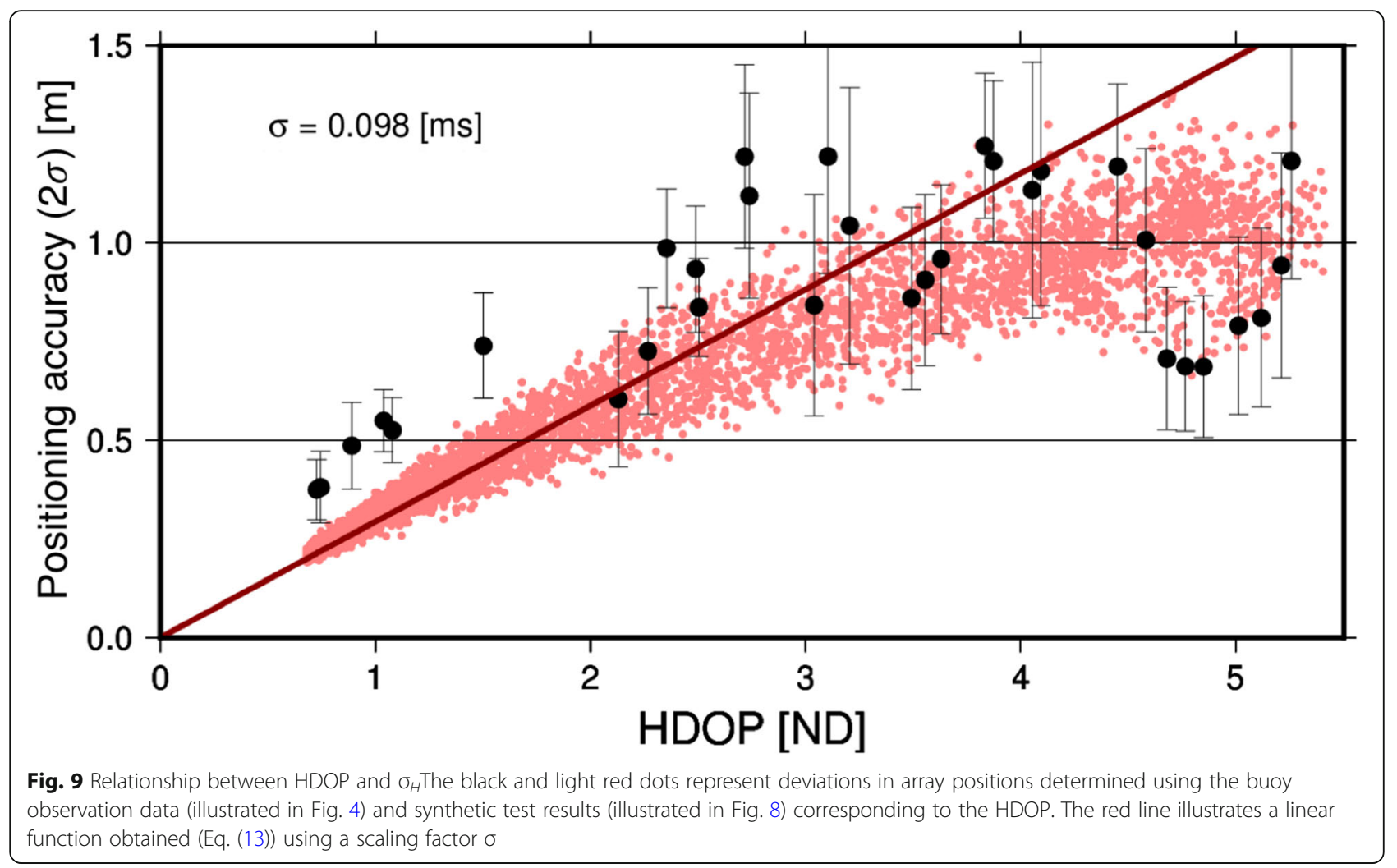

0.39 versus $1.5 \mathrm{~m}$, respectively. This indicates that buoybased measurement has the potential to be comparable in quality with ship-based measurement. Estimated array positions have two notable characteristics: the accuracy is degraded outside the array, and the deviation of array positions is large in the direction of the line of sight from an observation point to the array center. These characteristics were identified by means of DOP analysis, which uses the geometry between an observation point and PXP positions to calculate error ellipses. Error ellipses can illustrate and quantify the anisotropy in accuracy in both buoy- and ship-based data. To confirm the applicability of the assessment of positioning accuracy using error ellipses for an arbitrary observation point, we performed numerical synthetic testing of error propagation over the entire area of the drifting range of the buoy. The error ellipses calculated using array positions in the synthetic tests exhibited patterns quite similar to those of the error ellipses obtained by the DOP analysis approach. Error ellipses can be translated into positioning accuracies using a scaling factor that is the common standard deviation of residuals of travel time when an array position is estimated using all pings. We obtained the common standard deviation of the residuals of the travel times, $0.098 \mathrm{~ms}$, and confirmed that the positioning accuracy predicted by the translation corresponded to that calculated using array positions from buoy-based observations. The error ellipses obtained from DOP analysis and the positioning accuracy obtained by translation of the error ellipses determined using the standard deviation of travel time residuals enable a detailed assessment of the accuracy, including the directional accuracy of buoy-based GNSSA data immediately after an earthquake.

\section{Additional file}

Additional file 1: Figure S1. Chart table of three observation campaigns for individual PXP positioning. Each set of observations consists of moving and/or point survey data. Figure S2. Time series of round-trip traveltimes obtained during moving and point surveys in Campaign 2. The traveltimes between the transducer and the PXPs are indicated by colored dots. Figure S3. Individual PXP positioning results. The colored dots and black lines indicate the observed and modeled NTD, respectively. Figure S4. Time series of round-trip traveltimes obtained during continuous observation using a moored buoy. The dots, representing the traveltimes, are color coded in the same way as in Additional file 1 Figure S2. Figure S5. Attitude angle of the buoy from GNSS gyro during continuous observation. The plots on the left and in the center show the heading, pitch, and roll of the buoy from top to bottom during (a) the entire period until the occurrence of missing data (after mid-October 2016) and (b) a 20-minute period of a GNSS-A observation sequence on 21 March 2016. (c) Power spectrum of the attitude angle on 21 March 2016. The colored lines correspond to the same spectra of heading, pitch, and roll as in (b). The characteristic periods were $3-4 \mathrm{sec}$ in pitch and roll and 30-50 sec in pitch, roll and heading. Figure S6. Map view of DOPs using our array geometry. (a) EDOP, (b) NDOP, and (c) HDOP. The large DOP region (colored in shades of blue) indicates that the poisoning accuracy suffers. The contour lines are DOP intervals of 0.5 . Figure S7. Map view of DOPs using outer three PXPs. (a) EDOP, (b) NDOP, and (c) HDOP. The color scale is the same as in 
Fig. S6. Black indicates a DOP value greater than 5 . Figure S8. Map views of components of Equation (8). (a) $D_{x x}$ (b) $D_{y y}$ and (c) $D_{x y}$. The gray circle indicates a radius of $4 \mathrm{~km}$ from the array center. (DOCX $2155 \mathrm{~kb}$ )

\section{Abbreviations}

JAMSTEC: Japan Agency for Marine-Earth Science and Technology; GEONET: GPS Earth Observation Network; DOP: Dilution of precision; EW: East-west; NS: North-south; UD: Up-down

\section{Acknowledgements}

This study was supported by JST Cross-ministerial Strategic Innovation Promotion Program (SIP, Reinforcement of resilient function for preventing and mitigating disasters), MEXT/JSPS Research Project for compound disaster mitigation on the great earthquakes and tsunamis around the Nankai Trough region and an activity of the Core Research Cluster of Disaster Science in Tohoku University (a Designated National University).

We thank the captains and the crews of the RN Kaiyou, Yokosuka, and Shinsei-maru, and we thank the marine technicians of Marine Works Japan for the buoy installation, its retrieval, and GNSS-A observations. We also thank Tsubone Satoshi for the maintenance of the buoy system.

\section{Authors' contributions}

$\mathrm{Ml}, \mathrm{MK}, \mathrm{CH}$, and $\mathrm{YO}$ proposed the topic, conceived and designed the study. TF and $\mathrm{HO}$ carried out the development of the buoy system. $\mathrm{CH}$ estimate attitude of the buoy using Xsens data. MK, $\mathrm{CH}, \mathrm{YO}$, and RT helped the interpretation of the result. All authors read and approved the final manuscript.

\section{Authors' information}

MI is a graduate student in Graduate School of Science, Tohoku University. MK is a professor in the International Research Institute for Disaster Science, Tohoku University. $\mathrm{CH}, \mathrm{YO}$, and $\mathrm{RH}$ are a research staff, an associate professor, and a professor in Research Center for Prediction of Earthquakes and Volcanic Eruptions, Tohoku University, respectively. NT is a principal research scientist in JAMSTEC and a Vice Director in Network Center for Earthquake, Tsunami and Volcano, National Research Institute for Earth Science and Disaster Resilience. FT and $\mathrm{HO}$ are a chief engineer and a coordinator in JAMSTEC, respectively.

\section{Funding}

This study was supported by JST Cross-ministerial Strategic Innovation Promotion Program (SIP, Reinforcement of resilient function for preventing and mitigating disasters), MEXT/JSPS Research Project for compound disaster mitigation on the great earthquakes and tsunamis around the Nankai Trough region and an activity of the Core Research Cluster of Disaster Science in Tohoku University (a Designated National University)

\section{Availability of data and materials}

Data sharing is not applicable to this article as no datasets were generated during the current study. Please contact the corresponding author for data requests.

\section{Competing interests}

The authors declare that they have no competing interests.

\section{Author details}

Graduate school of Science, Tohoku University, 6-3 Aza-aoba, Aramaki, Aoba-ku, Sendai, Miyagi 980-8578, Japan. ${ }^{2}$ International Research Institute for Disaster Science, Tohoku University, 468-1 Aza-aoba, Aramaki, Aoba-ku, Sendai, Miyagi 980-8572, Japan. ${ }^{3}$ Research Center for Prediction of Earthquakes and Volcanic Eruptions, Tohoku University, 6-6 Aza-aoba, Aramaki, Aoba-ku, Sendai, Miyagi 980-0845, Japan. ${ }^{4}$ National Research Institute for Earth Science and Disaster Resilience, Tennodai, Tsukuba, Ibaraki 305-0006, Japan. ${ }^{5}$ Research and Development Center for Earthquake and Tsunami, Japan Agency for Marine-Earth Science and Technology, 3173-25 Showa-machi, Kanazawa-ku, Yokohama, Kanagawa 236-0001, Japan. ${ }^{6}$ Department of Marine Technology Development, Japan Agency for Marine-Earth Science and Technology, 2-15 Natsushima-cho, Yokosuka, Kanagawa 237-0061, Japan.
Received: 29 March 2019 Accepted: 25 July 2019

Published online: 12 August 2019

\section{References}

Chadwell CD (December 2016) (2016) Initiation of GPS-Acoustics measurements on the continental slope of the Cascadia subduction zone. AGU Fall Meeting 2016, Moscone Center. San Francisco:12-16

Chen HY, Ikuta R, Lin CH, Hsu YJ, Kohmi T, Wang CC, Yu SB, Tu Y, Tsujii T, Ando $M$ (2017) Back-Arc Opening in the Western end of the Okinawa trough revealed from GNSS/Acoustic measurements. Geophys. Res. Lett 45:137-145

Fujita M, Ishikawa T, Mochizuki M, Sato M, Toyama S, Katayama M, Kawai K, Matsumoto Y, Yabuki T, Asad A, Colombo OL (2006) GPS/Acoustic seafloor geodetic observation: method of data analysis and its application. Earth Planets Space 58:265-275

Fukuda T, Ishihara Y, Ochi H, Deguchi M, Takahashi N, Imai K, Kido M, Ohta Y, Imano M, Miyoshi S, Yamada H (2017) Development of an on-demand monitoring buoy system for crustal deformation. BlueEarth Symposium:2017, BE17-P69, CST Nihon University, Tokyo, 2-3 March 2017

Honsho C, Kido M (2017) Comprehensive analysis of traveltime data collected through GPS-Acoustic observation of seafloor crustal movements. J Geophys Res 122:8583-8599

Honsho C, Kido M, Ohta Y, Imano M (2015) Monitoring of moored buoy attitude by single GPS antenna and rate-gyro. 124th meeting of the Geodetic Society of Japan, Fukuoka, Kyushu University, 14-16 October 2015

Imano M, Kido M, Ohta Y, Fukuda T, Ochi H, Takahashi N, Hino R (2015) Improvement in the accuracy of real-time GPS/Acoustic measurements using a multi-purpose moored buoy system by removal of acoustic multipath. In: Hashimoto M (ed) International Symposium on Geodesy for Earthquake and Natural Hazards (GENAH). International Association of Geodesy Symposia, vol 145. Springer, Heidelberg, pp 105-114

Imano M, Kido M, Ohta Y, Fukuda T, Ochi H, Takahashi N, Honsho C, Hino R (2017) Accuracy of a continuous/on-demand GPS/Acoustic seafloor positioning using a slackly moored buoy in the Kuroshio region. IAG-IASPEI, Kobe, Kobe International Conference Center, 30 July-4 August 2017

Ishihara Y, Ochi H, Fukuda T, Takahashi N, Kaneda Y, Sugiyama T (2012) Tsunami warning buoy system and an acoustic telemetry system for high current area. Abstracts of tsunami workshop by Sentiel Asia, Sendai International Center, Sendai, 3 July 2012

Kaplan ED, Hegarty CJ (2006) Understanding GPS: principles and applications, Second Edition. Artech House, Boston

Kato T, Terada Y, Kinoshita M, Kakimoto H, Isshiki H, Matsuishi M, Yokoyama A, Tanno T (2000) Real-time observation of tsunami by RTK-GPS. Earth Planets Space 52:841-845

Kato T, Terada Y, Nishimura H, Nagao T, Koshimura S (2011) Tsunami records due to the 2010 Chile Earthquake observed by GPS buoys established along the Pacific coast of. Japan

Kato T, Terada Y, Tadokoro K, Kinugasa N, Futamura S, Toyoshima M, Yamamoto S, Ishii M, Tsugawa T, Nishioka M, Takizawa K, Shoji Y, Seko S (2018) Development of GNSS buoy for a synthetic geohazards monitoring system. J. Dis. Res 13:460-471

Kido M (2007) Detecting horizontal gradient of sound speed in ocean. Earth, Planets Space 59:e33-e36

Kido M, Fujimoto H, Miura S, Osada Y, Tsuka K, Tabei T (2006) Seafloor displacement at Kumano-nada caused by the 2004 off Kii Peninsula earthquakes, detected through repeated GPS/Acoustic surveys. Earth Planets Space 58:911-915

Kido M, Imano M, Ohta Y, Fukuda T, Takahashi N, Tsubone S, Ihihara Y, Ochi H, Imai K, Honsho C, Hino R (2018) Onboard realtime processing of GPSacoustic data for moored buoy-based observation. J Dis Res 13(3):472-488

Kido M, Osada Y, Fujimoto H, Hino R, Ito Y (2011) Trench-normal variation in observed seafloor displacements associated with the 2011 Tohoku-Oki earthquake. Geophys Res Let 38:L24303. https://doi.org/10.1029/2011GL050057

Langley BR (1999) Dilution of precision. In: GPS World. Available via DIALOG. http://www2.unb.ca/gge/Resources/gpsworld.may99.pdf. Accessed May 1999

Sato M, Ishikawa T, Ujihara N, Yoshida S, Fujita M, Mochizuki M, Asada A (2011b) Displacement above the hypocenter of the 2011 Tohoku-Oki Earthquake. Science 332:1395

Sato M, Saoto H, Ishikawa T, Matsumoto Y, Fujita M, Mochizuki M, Asada A (2011a) Restoration of interplate locking after the 2005 Off-Miyagi Prefecture 
earthquake, detected by GPS/acoustic seafloor geodetic observation. Geophys Res Let 38:L01312. https://doi.org/10.1029/2010GL045689

Spiess FN (1985) Suboceanic geodetic measurements. IEEE Trans Geosci. Remote Sens GE-23:502-510

Spiess FN, Chadwell CD, Hildeblanda JA, Young LE, Purcell GH Jr, Dragert H (1998) Precise GPS/Acoustic positioning of seafloor reference points for tectonic studies. Phys Earth Planet Inter 108(2):101-112

Sun T, Wang K, linuma T, Hino R, He J, Fujimoto H, Kido M, Osada Y, Miura S, Ohta Y, Hu Y (2014) Prevalence of viscoelastic relaxation after the 2011 Tohoku-oki earthquake. Nature 514:84-87

Tadokoro K, Ikuta R, Watanabe T, Ando M, Okuda T, Nagai S, Yasuda K, Sakata T (2012) Interseismic seafloor crustal deformation immediately above the source region of anticipated megathrust earthquake along the Nankai Trough, Japan. Geophys. Res. Lett 39:L10306. https:/doi.org/10.1029/2012GL051696

Takahashi N, Imai K, Ishihara Y, Fukuda T, Ochi H, Suzuki K, Kido M, Ohta Y, Imano M, Hino R (December 2017) (2017) Real-time and on-demand buoy observation system for tsunami and crustal displacement. AGU Fall Meeting. New Orleyns:11-15

Takahashi N, Ishihara Y, Fukuda T, Ochi H, Harada J, Mori T, Deguchi M, Kido M, Ohta Y, Hino R, Mutoh K, Hashimoto G, Motohashi O Kaneda Y (2015) Buoy platform development for observation of tsunami and crustal deformation. In: Hashimoto M (ed) International Symposium on Geodesy for Earthquake and Natural Hazards (GENAH). International Association of Geodesy Symposia, vol 145. Springer, Heidelberg, pp 97-103

Takahashi N, Ishihara Y, Ochi H, Fukuda T, Tahara J, Maeda Y, Kido M, Ohta Y, Mutoh K, Hashimoto G, Kogure S, Kaneda Y (2014) New buoy observation system for tsunami and crustal deformation. Mar Geophys Res 35:243-253

Taraldsen G (2011) Dilution of Precision in Acoustics, 34th Scandinavian Symposium on Physical Acoustics, Geilo, pp 30 January-30 Januar2 February 2011

Terada Y, Kato T, Nagai T, Kawaguchi K, Koshimura S, Matsushita Y (2013) An improvement of the GPS buoy system for detecting tsunami at far offshore. Book of Abstract, the International Association of Geodesy (IAG) Scientific Assembly 2013:409

Terada Y, Kato T, Nagai T, Koshimura S, Imada N, Sakaue H, Tadokoro K (2015) Recent developments of GPS tsunami meter for a far offshore observations. In: Hashimoto M (ed) International Symposium on Geodesy for Earthquake and Natural Hazards (GENAH). International Association of Geodesy Symposia, vol 145, pp 145-153

Tomita F, Kido M, Ohta Y, linuma T, Hino R (2017) Along-trench variation in seafloor displacements after the 2011 Tohoku earthquake. Sci Adv 3:2375-2548

Tomita F, Kido M, Osada Y, Hino R, Ohta Y, linuma T (2015) First measurement of the displacement rate of the Pacific Plate near the Japan Trench after the 2011 Tohoku-Oki earthquake using GPS/acoustic technique. Geophys Res Lett 42:8391-8397

Watanabe S, Sato M, Fujita M, Ishikawa T, Yokota Y, Ujihara N, Asada A (2014) Evidence of viscoelastic deformation following the 2011 Tohoku-Oki earthquake revealed from seafloor geodetic observation. Geophys Res Lett 41:5789-5796

Yasuda K, Tadokoro K, Taniguchi S, Kimura H, Matsuhiro K (2017) Interplate locking condition derived from seafloor geodetic observation in the shallowest subduction segment at the Central Nankai Trough, Japan. Geophys. Res. Lett. 44. https://doi.org/10.1002/2017GL072918

Yokota Y, Ishikawa T, Watanabe S, Tashiro T, Asada A (2016) Seafloor geodetic constraints on interplate coupling of the Nankai Trough megathrust zone. Nature 534:374-377

Zumberge JF, Heflin MB, Jefferson DC, Watkins MM, Webb FH (1997) Precise point positioning for the efficient and robust analysis of GPS data from large networks. J Geophys Res 102:5005-5017

\section{Publisher's Note}

Springer Nature remains neutral with regard to jurisdictional claims in published maps and institutional affiliations.

\section{Submit your manuscript to a SpringerOpen ${ }^{\circ}$ journal and benefit from:}

- Convenient online submission

- Rigorous peer review

- Open access: articles freely available online

- High visibility within the field

- Retaining the copyright to your article

Submit your next manuscript at $\boldsymbol{\nabla}$ springeropen.com 